\title{
CORRECTION
}

Open Access

\section{Publisher Correction to: Cognitive Research: Principles and Implications, volume 4}

Cognitive Research: Principles and Implications

\section{Publisher's correction to: Cognitive Research: Principles} and Implications, volume 4

An error occurred during the publication of a number of articles in Cognitive Research: Principles and Implications. Several articles were published in volume 4 with a duplicate citation number.

In this correction article the old and new citation metadata are published in Table 1.

The original articles have been updated. The publisher apologizes for the inconvenience caused to our authors and readers.

Table 1 Overview of incorrect and correct citation metadata

\begin{tabular}{lll}
\hline DOI & $\begin{array}{l}\text { Incorrect citation } \\
\text { number }\end{array}$ & $\begin{array}{l}\text { Correct citation } \\
\text { number }\end{array}$ \\
\hline $10.1186 / s 41235-019-0166-3$ & 5 & 18 \\
$10.1186 / s 41235-019-0167-2$ & 4 & 17 \\
$10.1186 / s 41235-019-0168-1$ & 1 & 16 \\
$10.1186 / s 41235-019-0170-7$ & 3 & 19 \\
$10.1186 / s 41235-019-0172-5$ & 2 & 20 \\
\hline
\end{tabular}

Published online: 09 August 2019

\footnotetext{
* Correspondence: info@biomedcentral.com

The original article can be found online at https://doi.org/10.1186/s41235-01 9-0172-5

London, UK
} 